\title{
Installation And Implementation of Energy Management Sytem in the Residential Buildings for Sustainable Development
}

\author{
Viswanathan Ganesh, S. Senthilmurugan, Akash Prabhu, Nirmal.A, Balaaji Varun V
}

\begin{abstract}
This paper presents the details of the installation of the energy management system in the buildings of a typical Residential Building Residential Building in India and consequently the reduction of electrical energy consumption. Increasing People intake, the introduction of new courses, research centers and laboratories, and the rapid expansion of Residential Building infrastructure, are rapidly increasing the demand for electricity in universities. Most of the electrical energy consumed in universities in India is for air conditioning and lighting purposes. Established Building Energy Management System (BMS) continuously monitors the electrical load demand of air handling units (AHUs) and room lighting in buildings and reduces the load demand by fitting the AHU thermostats based on the work schedule. One day and on / off control of occupancy based on occupancy in different rooms from remote server rooms via Ethernet. Preliminary findings suggest that a significant reduction in load demand can be achieved in any Residential Building in India through the implementation of BMS, thereby contributing to the reduction of domestic oil consumption. If most universities in the country installed BMS on their Residential Buildinges, it would be possible for electric utilities to use real-time meter data, technology-enabled dynamic pricing, and decisive direct load control for fuel management. There are Residential Buildinges. This paper also highlights the future trend in BMS implementation in universities, as the Residential Building's DSM has a secure Residential Building area network that can effectively use demand response when enabled by high-bandwidth, two-way, end-to-end. Can. Communication in a smart grid environment.
\end{abstract}

Keywords : Area Network,Building Energy,Demand Side Management ,India Introduction,Management System

\section{INTRODUCTION}

India is one of the top countries in the world that shows strong economic and industrial growth, and with these developments, its energy demand and hence oil itself is growing at an alarming rate. At this rate, energy consumption doubles in a decade and triples in two decades. Although the country has increased its production capacity by $20 \%$ over the past decade, it is still difficult to meet electricity demand during the summer.

Revised Manuscript Received on February 05, 2020

* Correspondence Author

Ganesh, studying B. Tech EEE in SRM Institute of Science and Technology, Kattankulathur, India.

S.Senthilmurugan, pursuing Ph.D. in EEE from SRM Institute of Science of Technology, Kattankulathur, India

Akash Prabhu, studying B. Tech EEE in SRM Institute of Science and Technology, Kattankulathur, India.

Nirmal.A, studying B. Tech EEE in SRM Institute of Science and Technology, Kattankulathur, India

Balaaji Varun, studying B. Tech EEE in SRM Institute of Science and Technology, Kattankulathur, India.

(C) The Authors. Published by Blue Eyes Intelligence Engineering and Sciences Publication (BEIESP). This is an open access article under the CC BY-NC-ND license (http://creativecommons.org/licenses/by-nc-nd/4.0/)
Apart from economic and industrial development in the country, population growth, hot weather and low electricity rates in the country are the other driving factors for this situation. The nation's economy tends to rely heavily on sustainable fuel consumption, which inhibits the government's ability to provide for domestic welfare and services.

In this scenario, the efficient use of valuable oil and gas resources is vital to the country's sustainable economic stability. The fastest immediate response is to implement demand side management and energy conservation measures, which can reduce system losses and electric power consumption [1]. It also provides a cushion for future energy diversification and other long-term plans. This paper presents the results of a preliminary investigation of demand-side management by installing energy management systems in some of the main premises of the buildings.

Energy efficiency is an important issue for Residential Building buildings because it is linked to People comfort and indoor air quality. Residential area has over 52 Residential Buildings. Electricity consumption is always increasing rapidly during the summer. As a result, the Residential Building spends a significant amount of energy consumption every year, even with very affordable electricity costs in India compared to other major countries in the world. Therefore, it is imperative to implement Residential Building energy management policies to promote energy conservation on Residential Building. To achieve this, a web-based fuel management and control system for the reduction of the load demand of some Residential Building buildings has been established, and this paper discusses the system description and pilot study conducted in these buildings. This paper also highlights a future trend in the implementation of BMS in universities, using the Residential Building area network of the Residential Building's DSM to effectively utilize demand response using recent developments in information and communication technologies.

\section{BUILDING ENERGY MANAGEMENT SYSTEM}

The Building Power System (BMS) automatically monitors and regulates building services, including air conditioning, ventilation, heating, lighting and other energy users inside a building or sometimes in groups of buildings. As part of the pilot investigation, RESIDENTIAL BUILDING provided housing with BMS for automated control of occupancy, duct, lights and air handling units (AHUs) in buildings 29, 40 and 51 of the main Residential Building. There are sensors to monitor Temperature and air quality in the Classroom and office. 
The dumper actuator is also a part of the BMS installed in these buildings. Building 29 has 19 classrooms. Occupancy sensors are installed in all 19 classrooms, 5 corridors and lobbies.

In Building 40, 20 occupancy sensors were provided in the classrooms. Building 51 includes 30 office rooms and a conference room, with an occupancy sensor available. These sensors have a medium range of up to 28 meters in length. The 29, 40 and 51 buildings have 16, 8 and 8 AHUs respectively. Each digital controller and control panel of these buildings are connected to the server in the control room via Ethernet.

Server Room 29 is under construction for 40, 29 and 51 buildings. Motors in the AHU can be converted to variable frequency drives to enable speed adjustment, as the thermostat setting is varied. Details of installation of BMS in various buildings are given in Table 1 . Figure 1 represents a screen shot of the occupancy status of each location in buildings. The green color indicates that the rooms are occupied and that there are lights in these rooms. As shown in fig. Screen shot of the air handling unit indicates the unit number, compressor status, temperature set and current schedule, return air temperature, fan speed and fresh air damper location. Any AHU can be turned on or off individually or in groups, from the server room or from any PC or laptop pressed anywhere in the world, which can be configured accordingly. This feature is especially useful for any emergency, which can be viewed from the monitor screen. Additionally, SMS alerts configured for mobile and PC can be sent on the spot in case of an emergency such as short-circuit and fire. As shown in Fig.3, a schematic diagram of a building's BMS, thermostat adjustment of AHUs, and the on-off control of the lights in the building can be done from the server's computer to the respective digital / related direct digital controllers. (DDCs)

\section{FUTURE POSSIBILITIES OF DSM IN UNIVERSITIES}

Future power networks rely heavily on a set of Intelligent Communication and Control technologies [2]. Most demand-side management programs currently in development countries focus primarily on the interaction between the utility company and its customers / customers. With the installation of the BMS discussed in the previous section, it is possible to reduce waste and reduce energy consumption and electricity bills without affecting the comfort of Peoples and faculty members on Residential Building. Once the BMS is implemented in all buildings on Residential Building, the utility can interfere with the power network through the advanced metering infrastructure as shown in Fig. 4. The energy management gateway to the image ensures a secure connection through the utility network with premises building loads such as AHUs, elevators, lights, etc. Server nodes and Residential Building area networks. The server collects information about the state of AHUs, lifts, pumps, lights and other electrical equipment through node sensors and microcontrollers. The data received from the Residential Building Area Network (CAN) sensors is routed through the server nodes to the Energy Management Unit (EMU) and communicates the control from the EMU to various load points. Users registered with the gateway can also take control orders from the utility. By introducing incentives and attractive dynamic pricing strategies, power companies can initiate initiatives to implement similar setups across different Residential Buildings, encouraging them to actively participate in demand side management and energy efficiency improvement programs [3]. Once customers start getting information about their energy usage on a real-time basis, they can adjust the duration and magnitude of power consumption based on dynamic prices at that time. Direct control of specific loads such as HVAC can also be done in emergency situations [4]. Thus, the two communication channels determine the Residential Building Residential Building's involvement in the utility's DSM strategies. In the coming years, users autonomy and distributed demand-side energy management systems [5] will be used to secure two-way digital communication infrastructure in future smart grids. In real time, it is possible to communicate frequent price updates to follow the development of a balance between supply and demand. In addition, this technological change has the potential to automate the load-transfer process, in which intelligent devices turn on or off themselves in an attempt to align consumer preferences and goals with advertised power prices. The integration of low-cost wireless power management systems, real-time meter data monitoring, flexible auto DR load control and aggregation management into future DSM programs [6]. DSM programs are not only efficient and affordable for future smart grids, they are also expected to be more secure from cyber-attacks.

\begin{tabular}{|c|c|c|c|c|}
\hline TABLE I. PROVISION OF EMS FACILITY IN BUILDINGS \\
\hline Details & Building 29 & Building 40 & Building 51 & Total \\
\hline A/C Units & 10 & 4 & 6 & 20 \\
\hline $\begin{array}{c}\text { DDC Panel } \\
\text { (HVAC) }\end{array}$ & 2 & 1 & 1 & 4 \\
\hline $\begin{array}{c}\text { DDC Panel } \\
\text { (Lighting) }\end{array}$ & 1 & 1 & 1 & 3 \\
\hline $\begin{array}{c}\text { Variable } \\
\text { Frequency Drives }\end{array}$ & 10 & 4 & 6 & 20 \\
\hline $\begin{array}{c}\text { Occupancy } \\
\text { Sensors }\end{array}$ & 18 & 20 & 32 & 70 \\
\hline $\begin{array}{c}\text { Suct Temperature } \\
\text { Sensors }\end{array}$ & 16 & 8 & 8 & 32 \\
\hline $\begin{array}{c}\text { Air Quality } \\
\text { Damper Actuators }\end{array}$ & 16 & 0 & 4 & 20 \\
\hline
\end{tabular}

Published By: 


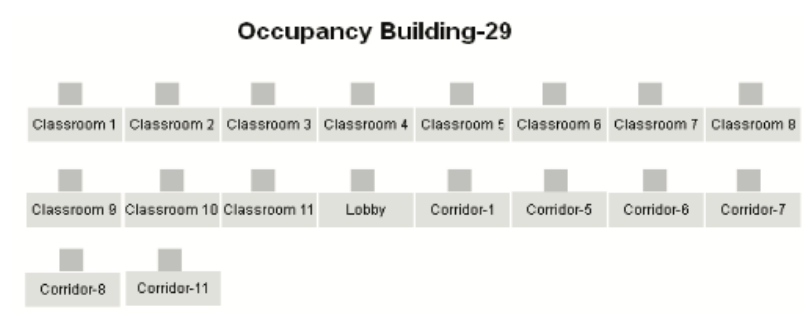

Occupancy Building-40
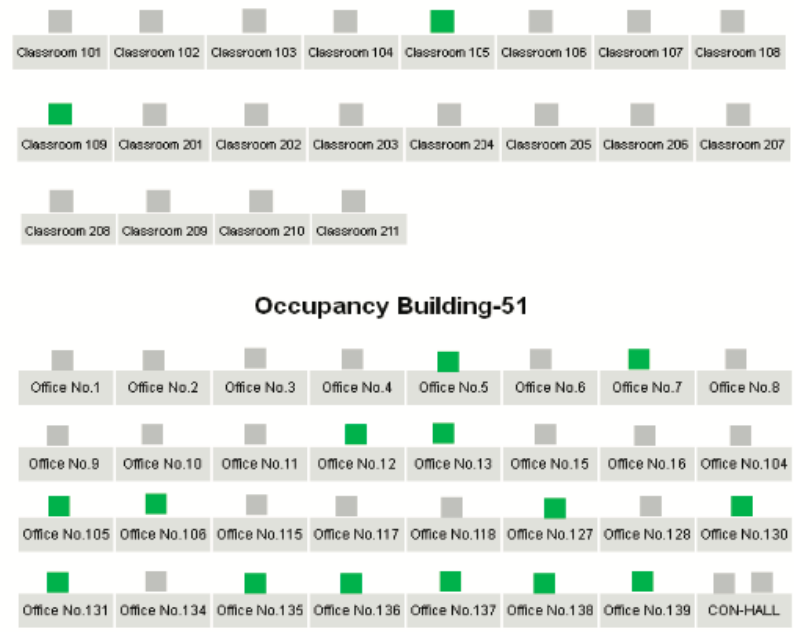

Fig. 1 Screen shot: Occupancy Status in Buildings 29,40 and 51

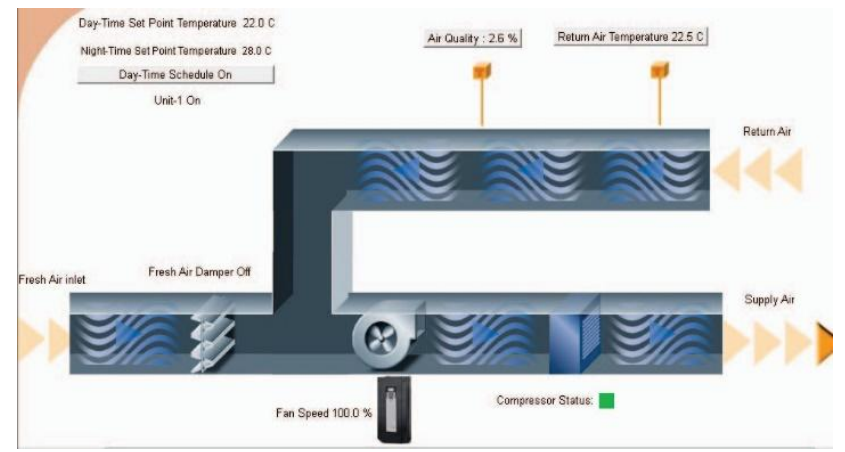

Fig. 2 Screenshot of Air Handling Unit 1

\section{SYSTEM DATA AND RESULTS}

Load management programs, which primarily focus on load demand reduction, are an effective tool for managing the maximum demand losses faced by utilities. The impact of BMS installed in buildings on main Residential Building in reducing energy consumption is presented in this section in relation to building volume. 51 . The building is used by the security and security department employees. The Residential Building and offices are occupied by employees despite regular class or months of vacation. The building has 31 office rooms and a conference room, and each of these rooms offers an MI-series occupancy sensor. Building number 51 has eight AHs with eight TH ratings, each unit meets the AC requirements of four rooms separate groups. They are provided with AHU wet actuators and sensors for duct temperature and air quality. Compressor motors for all eight AHUs have been converted into variable frequency drives of $5.5 \mathrm{~kW}$ to adjust the motor speed as the AHU's thermostat settings are varied and thereby improve motor efficiency.

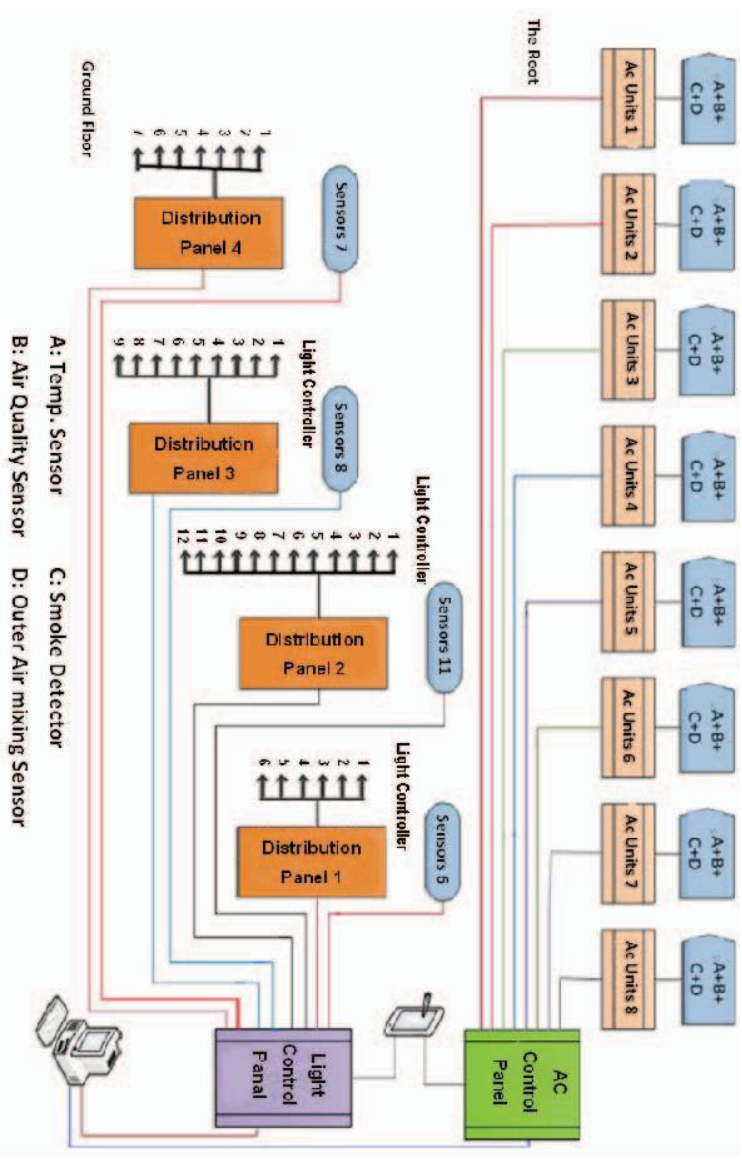

Fig. 3 Schematic diagram of the BMS in a building

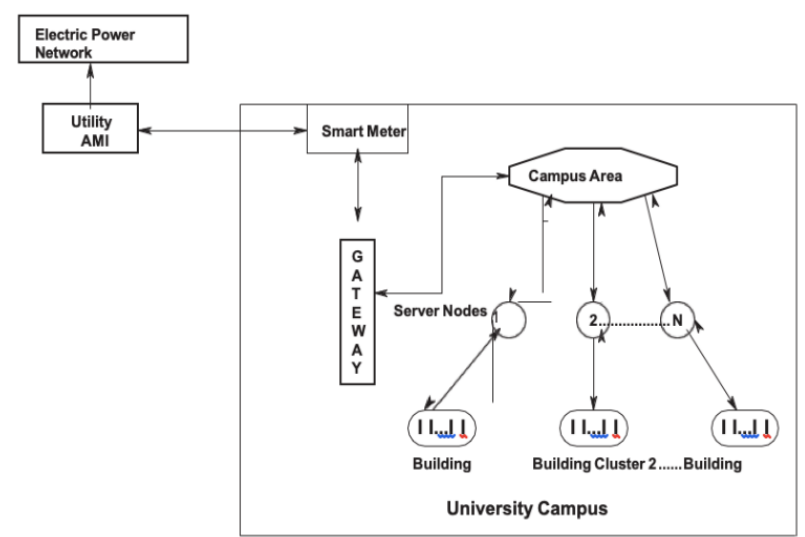

Fig. 4 Residential Building Area Network Interface with Utility Power Network

The total connected HVAC and lighting load in the building is $748 \mathrm{~kW}$ controlled by two different DDC panels. Electric load demand data as well as phase voltages and building currents are monitored continuously throughout the day and thereby for 30 minutes throughout the year. This instant interval data stored on digital meters is then transferred to personal computers for further analysis. The maps of average power demand obtained from interval data for August 2019 and August 2019, respectively, are shown in Fig. 3.5 and Fig. Are given in 6. The results for August 2019 can be obtained from data that existed prior to the installation of the BMS in the building, and from the date of installation until August 2019.

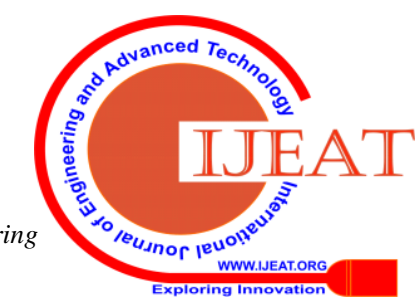


From these statistics we can see the energy consumption trend in this building. Each week in these months corresponds to any particular day, usually following a similar pattern. Also, energy consumption on Fridays is lower compared to other days in these two months. Because Friday is a holiday. The impact of BMS on the building can be clearly seen from the energy consumption results for Fridays during these months. The results in 6 are consistent with the AHU thermostats, so the room temperature of 20DC is between $6 \mathrm{am}$ and 12.00 in the daytime and $24^{\circ} \mathrm{C}$ at night and 12.00 and 6.00 in the morning. The speed of VFDs at night is set at $50 \%$ when the temperature setting is increased. On the other hand, in August 2019, the thermostats are set to 20 and $\mathrm{C}$, and the motor is operating at $100 \%$ speed throughout the day. Fig. 5 and Fig. Compared to 6, it can be assumed that BMS can significantly reduce the energy consumption in the building during the holidays. Furthermore, it can be edited from Fig.7 that the average electricity demand for the month of August 2019 is very low compared to August 2019. Total energy consumption during these months was $58883.2 \mathrm{kWh}$ and $50456.0 \mathrm{kWh}$, respectively, so energy consumption was equal to $14.31 \%$ in August 2019 after BMS was established. If not for a month BMS. The main contribution to reducing load demand these days is to reduce air conditioning and lighting load. Automatic monitoring and control by BMS. It is possible to save more energy by fine tuning and bookkeeping of BMS operation.

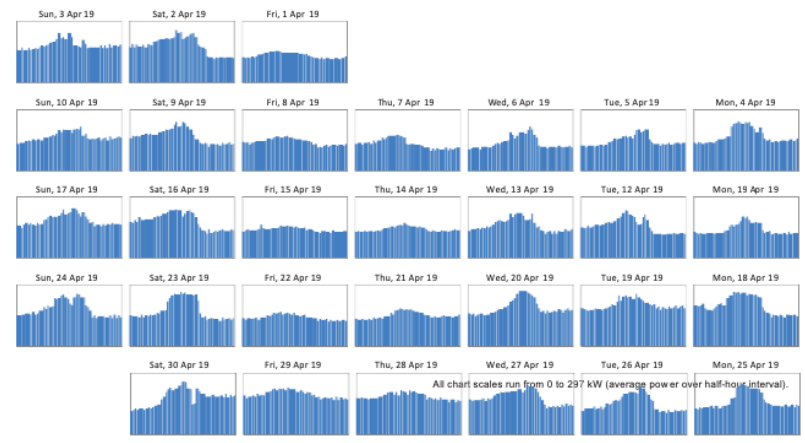

Fig. 5 Chart of Energy Consumption in Building No 51 for the Month of August 2019, Before the Installation of BMS
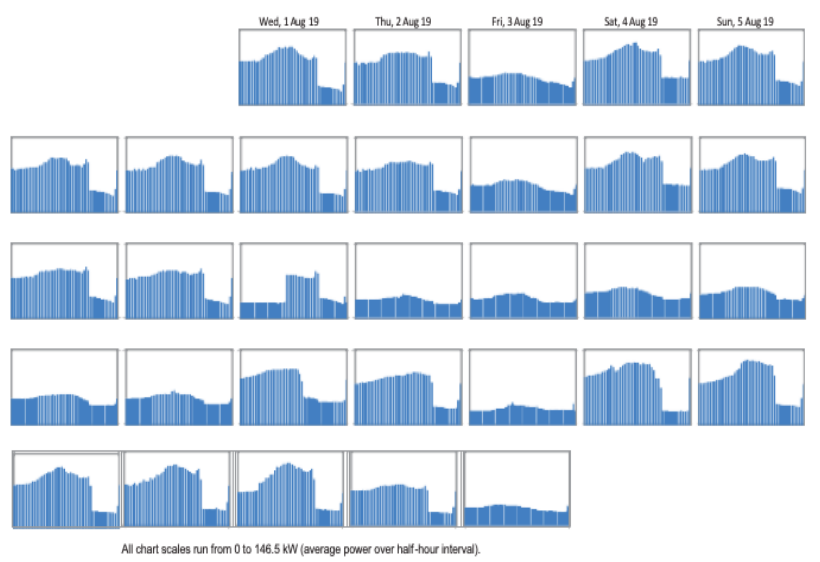

Fig. 6 Chart of Energy Consumption in Building No 51 for the Month of August 2019, After the Installation of BMS

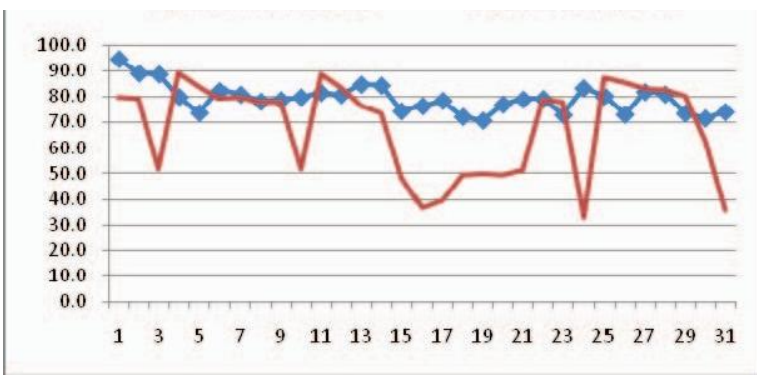

Fig.7 Effect of BMS in Daily Average Energy Consumption in Building 51 August 2019 Without BMS and August 2019 with BMS

\section{CONCLUSION}

Fuel consumption and hence the need for oil for domestic use in India is growing at an alarming rate, so it is imperative to implement DSM effectively by utilizing the latest developments in information and communication technologies. This paper discusses the details of BMS installed at some of the main Residential Building of General results and future prospects of Residential Building DSM are also presented. Building area networks that respond to research and development and utility and grid cost signals in secure wireless EMS offer the opportunity to enhance the effectiveness of future DSP programs.

\section{REFERENCES}

1. Goran Strbac, "Demand side management: benefits and challenges," International Journal of Energy Policy, Vol 36, pp. 4419-4426, 2008.

2. C. Wei, " A conceptual framework of smart grid," Power and Energy Engineering Conference (APPEEC), pp.1-4, March 2010.

3. Fabrice Saffre and Richard Gedge, "Demand-side management for the smart grid," IEEE/IFIP Network Operations and Management Symposium Workshops, pp. 300-304, 2010.

4. Peter Palensky and Dietmar Dietrich, " Demand side management: demand response, intelligent energy systems, and smart loads," IEEE Transactions on Industrial Informatics, Vol. 7, No. 3, pp. 381-388, August 2019.

5. Amir-Hamed Mohsenian-Rad, Vincent W. S. Wong, Juri Jatskevich, Robert Schober and Alberto Leon-Garcia, "Autonomous demand-side management based on game-theoretic energy consumption scheduling for the future smart grid," IEEE Trans. on Smart Grid, Vol. 1, NO. 3, pp. 320- 331, December 2010.

6. Nikolaos Gatsis and Georgios B. Giannakis," Residential load control: distributed scheduling and convergence with lost AMI messages," IEEE Transactions on Smart Grid, Vol. 3, No. 2, pp.770-786, June 2010.

\section{AUTHORS PROFILE}

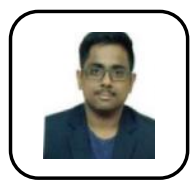

Viswanathan Ganesh, is a Third year UG Student. He is currently studying $B$. Tech EEE in SRM Institute of Science and Technology, Kattankulathur, India. He has also participated in many International Conferences and also published papers in many International Journals. His research interests are Smart grid, Energy Management,

Power Systems, Electrical Machines.

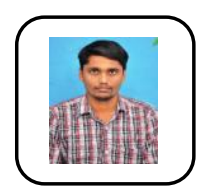

S.Senthilmurugan, received his Diploma in Electrical and Electronics Engineering from Alagappa Polytechnic college Karaikudi , DOTE, Chennai, India in 2004 with First class with Honours. He received his B.E. degree in Electrical and Electronics Engineering from Alagapaa Chettiar College of Engineering and Technology,Karaikudi (Anna University), India in 2007 with First class. 
He received his M.E. degree in Control and Instrumentation Engineering from College of Engineering Guindy, Anna University, India in 2010 with First class. He is currently pursuing Ph.D. in EEE from SRM Institute of Science of Technology, Kattankulathur, India. He is also an Assistant Professor (Sr.G) in the Department of Electrical and Electronics Engineering in SRM Institute of Science and Technology (SRMIST), Kattankulathur, India since 2011. He is also holding a position of Faculty Advisor of ENFUSE student chapter in SRMIST, Dept of Electrical and Electronics Engineering having 188 student members since 2018. This chapter actively involved in conducting workshops, Conferences, Industrial visits, Tech Quiz etc by creating awareness of Energy conservation and its management. His research interests are Control Systems, Smart Grid, Virtual Instrumentation, Sensor and Networks. He has also participated in many National and International Conferences and also published papers in many National and International Journals.

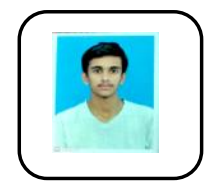

Akash Prabhu is a Third year UG Student. He is currently studying B. Tech EEE in SRM Institute of Science and Technology, Kattankulathur, India. He has also participated in many International Conferences and also published papers in many International Journals. His research interests are Smart grid, Energy Management, Power Systems, Electrical Machines.

Nirmal.A is a Third year UG Student. He is currently studying B. Tech EEE in SRM Institute of Science and Technology, Kattankulathur, India. $\mathrm{He}$ has also participated in many International Conferences and also published papers in many International Journals. His research interests are Smart grid, Energy Management, Power Systems, Electrical Machines.

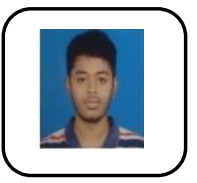

Balaaji Varun V is a Third year UG Student. He is currently studying B. Tech EEE in SRM Institute of Science and Technology, Kattankulathur, India. He has also participated in many International Conferences and also published papers in many International Journals. His research interests are Smart grid, Energy Management, Power Systems, Electrical Machines. 